\title{
Study on the reliability of the underground conveyor belt system installed at Vulcan Mine, the Jiu Valley Basin in Romania
}

\author{
Ovidiu-Bogdan Tomuș ${ }^{1, *}$, Andrei Andraș ${ }^{1}$, and Mihai Magyari ${ }^{2}$ \\ ${ }^{1}$ University of Petroșani. Dept. of Mechanical, Industrial and Transports Engineering, Romania \\ ${ }^{2}$ INCD Insemex Petroșani, Romania
}

\begin{abstract}
The paper deals with a comprehensive reliability analysis of the conveyor belts belonging to an underground coal mine in the Jiu Valley, Romania. As resulted from the mine management reports, the transportation system is responsible for many downtimes and is a real bottleneck in the constant and adequate production, and the suspicion is the weak state of belt conveyers, which are the spinal column of the extraction process. For this reason, a comprehensive reliability analysis has been decided, in order to deliver a maintenance-upgrading plan.
\end{abstract}

\section{Introduction}

Vulcan mine plant is one of the oldest underground hard coal mines in the Jiu Valley coalfield. Jiu Valley hard coal is mined out since 1850, actually in 4 plants, other 3 being in downsizing and closure process. Vulcan is one of active mines, belonging to the Hunedoara Energetic Complex, with an output of about $2 \mathrm{M}$. tons/year, with a foreseen lifespan until the year 2022. The location of Vulcan mining field in the layout of Jiu Valley coalfield can be seen in figure 1 [1].

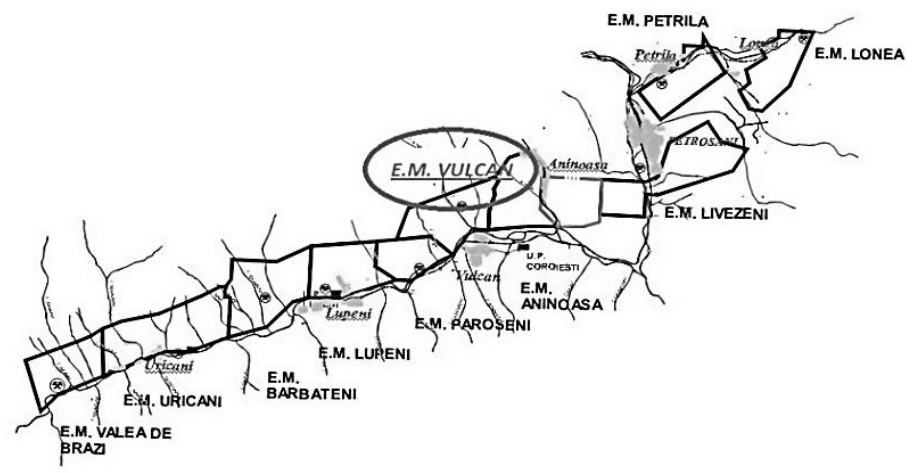

Fig. 1. The location of Vulcan mining field in the layout of Jiu Valley coalfield.

\footnotetext{
* Corresponding author: tobogdan2002@yahoo.com
} 
The mine plant, due to its age and the tectonics of the coal seams, has been developed on horizontal and vertical directions in a way which led to a very large extension. In plus, the used technology, specific to thick inclined seams in horizontal slices, with top coal caving, in the past 20 years, has as result a very complex and irregular structure of the conveying system, as can be seen in figure 2 [2].

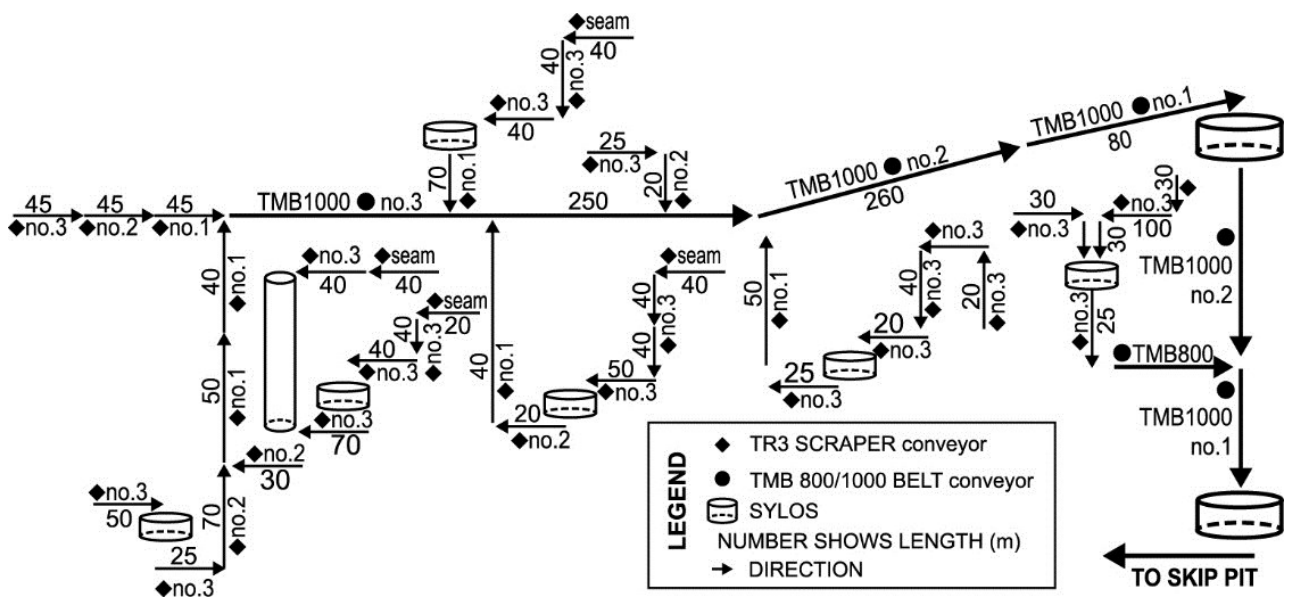

Fig. 2. Structure of the conveying system.

The main conveying system consist in belt conveyors TMB 800 and TMB 1000 (the figure indicating the width of the belt) on main gates at the levels 250, 315 and 360 (elevation related to the sea level) until the intermediary silos and finally to the main hoisting shaft [5].

As resulted from the mine management reports, the transportation system is responsible for many downtimes and is a real bottleneck in the constant and adequate production, and the suspicion is the weak state of belt conveyers, which are the spinal column of the extraction process [1].

For this reason, a comprehensive reliability analysis has been decided, in order to deliver a maintenance-upgrading plan.

\section{Reliability analysis of main belt conveyors}

The reliability study of the main belt conveyors at Vulcan mine plant, has been performed using the data from the conveyor system monitoring books taking into accounts the records in the period June 2012 - March 2013.

The structure and occurrence frequency of faults of the conveyors in the period are presented in table 1 and in figures 3 and 4.

Table 1. Structure of faults occurred at belt conveyors.

\begin{tabular}{|c|c|c|c|}
\hline \multirow{2}{*}{ No. } & \multirow{2}{*}{ Subassembly failed } & \multicolumn{2}{|c|}{ Absolute frequency of faults } \\
\hline & & No. of faults & $\%$ \\
\hline 1 & Belt - staples & 119 & 46.48 \\
\hline 2 & Upper and lower idlers & 76 & 29.69 \\
\hline 3 & Belt tensioning system & 37 & 14.45 \\
\hline 4 & Belt - requiring replacement & 11 & 4.30 \\
\hline 5 & Mechanical drive system & 7 & 2.74 \\
\hline 6 & $\begin{array}{l}\text { Line supports } \\
\end{array}$ & 6 & 2.34 \\
\hline & Total & 256 & 100.00 \\
\hline
\end{tabular}


The table above shows that the most frequent is the belt sections coupling staples, at about $47 \%$.

This kind of fault is more relevant because they are 9 conveyers, each with one, two or three joints, remediation of a failure paralyzing for about two-three hours all the haulage system, which dramatically influence the operation cycle in all working faces [4].

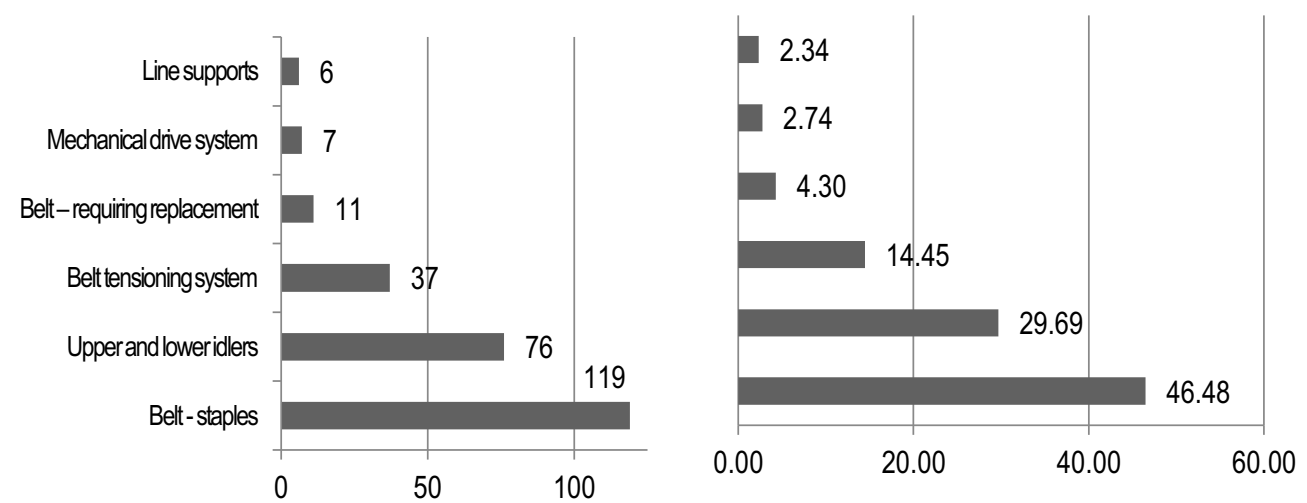

Fig. 3. Absolute frequency of faults.

Fig. 4. Relative frequency of faults in $\%$.

The idlers fault and replacement has a less impact on overall mining plant availability, despite their large amount, and its large share in total of faults - about $30 \%$ because of reduced time consumption for their replacement. The large share of staple joint faults in one year of operation was the main concern leading to the necessity of the present reliability analysis [2].

Analysing the occurrence of stapled joints failures, we selected from the overall 9 conveyors 3 ones which are similar length, working conditions and width of belt.

A factor which is more difficult to be quantified is the degree of ageing of belt's material, the three conveyors having, at the beginning of the study different operating hours.

Table 2. Empirical repartition function $\hat{F}\left(t_{i}\right)$ calculation.

\begin{tabular}{|c|c|c|c|c|}
\hline $\mathbf{i}$ & $\begin{array}{c}t_{i}, \\
\text { hours }\end{array}$ & $\begin{array}{c}\text { Absolute frequency, } \\
n_{i}\end{array}$ & $\begin{array}{c}\text { Relative frequency, } \\
f_{i}\end{array}$ & $\begin{array}{c}\text { Empirical repartition function, } \\
\hat{F}\left(t_{i}\right)\end{array}$ \\
\hline 1 & 50 & 9 & 0.097826 & 0.097826 \\
\hline 2 & 58 & 8 & 0.086957 & 0.184783 \\
\hline 3 & 60 & 21 & 0.228261 & 0.413043 \\
\hline 4 & 100 & 4 & 0.043478 & 0.456522 \\
\hline 5 & 110 & 3 & 0.032609 & 0.489130 \\
\hline 6 & 135 & 2 & 0.021739 & 0.510870 \\
\hline 7 & 147 & 6 & 0.065217 & 0.576087 \\
\hline 8 & 150 & 4 & 0.043478 & 0.619565 \\
\hline 9 & 154 & 3 & 0.032609 & 0.652174 \\
\hline 10 & 170 & 2 & 0.021739 & 0.673913 \\
\hline 11 & 200 & 8 & 0.086957 & 0.760870 \\
\hline 12 & 210 & 5 & 0.054348 & 0.815217 \\
\hline 13 & 220 & 7 & 0.076087 & 0.891304 \\
\hline 14 & 230 & 1 & 0.010870 & 0.902174 \\
\hline 15 & 250 & 1 & 0.010870 & 0.913043 \\
\hline 16 & 340 & 1 & 0.010870 & 0.923913 \\
\hline 17 & 400 & 1 & 0.010870 & 0.934783 \\
\hline
\end{tabular}




\begin{tabular}{|c|c|c|c|c|}
\hline $\mathbf{i}$ & $\begin{array}{c}t_{i}, \\
\text { hours }\end{array}$ & $\begin{array}{c}\text { Absolute frequency, } \\
n_{i}\end{array}$ & $\begin{array}{c}\text { Relative frequency, } \\
f_{i}\end{array}$ & $\begin{array}{c}\text { Empirical repartition function, } \\
\hat{F}\left(t_{i}\right)\end{array}$ \\
\hline 18 & 420 & 1 & 0.010870 & 0.945652 \\
\hline 19 & 460 & 1 & 0.010870 & 0.956522 \\
\hline 20 & 620 & 1 & 0.010870 & 0.967391 \\
\hline 21 & 760 & 2 & 0.021739 & 0.989130 \\
\hline 22 & 1100 & 1 & 0.010870 & 1,000000 \\
\hline & & 22 & 22 & \\
& & $\sum_{i=1}^{2} n_{i}=92$ & $\sum_{i=1} f_{i}=1,000000$ & \\
\hline
\end{tabular}

From the available data, we inferred the running hours until the failure, obtaining the time series as follows: $50 ; 50 ; 50 ; 50 ; 50 ; 50 ; 50 ; 50 ; 50 ; 58 ; 58 ; 58 ; 58 ; 58 ; 58 ; 58 ; 58 ; 60$; $60 ; 60 ; 60 ; 60 ; 60 ; 60 ; 60 ; 60 ; 60 ; 60 ; 60 ; 60 ; 60 ; 60 ; 60 ; 60 ; 60 ; 60 ; 60 ; 60 ; 88 ; 88 ; 88 ; 88$; $88 ; 88 ; 88 ; 88 ; 100 ; 100 ; 100 ; 100 ; 110 ; 110 ; 110 ; 135 ; 135 ; 147 ; 147 ; 147 ; 147 ; 147 ; 147$; $150 ; 150 ; 150 ; 150 ; 154 ; 154 ; 154 ; 170 ; 170 ; 200 ; 200 ; 200 ; 200 ; 200 ; 200 ; 200 ; 200 ; 210$; $210 ; 210 ; 210 ; 210 ; 220 ; 220 ; 220 ; 220 ; 220 ; 220 ; 220 ; 230 ; 250 ; 340 ; 400 ; 420 ; 460 ; 620$; $760 ; 760 ; 1100$

This statistical series have 92 values and it is a statistical series of type S2 with redundant values. For this series of running hours between two faults, the empirical repartition function, $\hat{F}\left(t_{i}\right)$ the calculi are presented in table 2 .

The values of the Empirical repartition function are calculated with the formula:

$$
\hat{F}\left(t_{i}\right)=\sum_{j=1}^{i-1} f_{j}, \quad \text { for } i=1,2, \ldots .22
$$

Considering the nature of the subassembly in the study, it is assumed that the times of failure, considered between two consecutive failures are distributed following a Weibull distribution law, as this will be confirmed or infirmed using concordance tests [4].

The probability density of failures for tri-parametric Weibull distribution is expressed by the relation:

$$
f(t ; \eta, \beta, \gamma)=\frac{\beta}{\eta}\left(\frac{t-\gamma}{\eta}\right)^{\beta-1} \exp \left[-\left(\frac{t-\gamma}{\eta}\right)^{\beta}\right]
$$

where $\beta$ is the shape parameter, $\eta$ is real scale parameter and $\gamma$ is the initializing parameter.

The parameters of a tri-parametric Weibull distribution can be calculated using the method of moments. The shape parameter $\beta$ is obtained by solving the equation:

$$
C V=\frac{\sqrt{\Gamma\left(\frac{2}{\beta}+1\right)-\left[\Gamma\left(\frac{1}{\beta}+1\right)\right]^{2}}}{\Gamma\left(\frac{1}{\beta}+1\right)}
$$

where $C V$ is the coefficient of variation, which is obtained using the relation

$$
C V=\frac{s}{m}
$$


where $s$ is the standard deviation and $\mathrm{m}$ is the mean value of the string.

The scale parameter $\eta$ is calculated with

$$
\eta=s / C_{\beta}
$$

and initializing parameter $\gamma$ with the relation

$$
\gamma=m-\eta K_{\beta}
$$

In these relations $K_{\beta}$ and $C_{\beta}$ are coefficients dependent on the shape parameter $\beta$, which are calculated from the relations:

$$
\begin{gathered}
K_{\beta}=\Gamma\left(\frac{1}{\beta}+1\right) \\
C_{\beta}=\sqrt{\Gamma\left(\frac{2}{\beta}+1\right)-\left[\Gamma\left(\frac{1}{\beta}+1\right)\right]^{2}}
\end{gathered}
$$

For the data above, with the mean value $m=288.363636$, standard deviation $s=$ 258.257447 and $C V=0.895596$ the parameters of the Weibull distribution are obtained are: $\beta=1,118460 ; \eta=300.455874$ ore $;=-9,0421 \times 10^{-5} ; K_{\beta}=0.959754 ; C_{\beta}=0.859552$.

By calculating the elements needed to define the distribution and verification of the Weibullian character of the analysed product behaviour using the Kolmogorov-Smirnov concordance test, we obtain the maximum distance, $D_{\max }=0.367631 \approx D_{\alpha, n}=D_{99,5,22}=$ $0.357818, D_{99,5,22} 0.085254<D_{\alpha, n}=D_{80.71}=0.124985, D_{80.71}$ being the KolmogorovSmirnov test feature for a confidence level of $99,5 \%$ and $n=22$ values, so that the Weibullian character of failure times distribution is validated.

The tri-parametric Weibull distribution parameters characteristics are calculated with the equations:

- Reliability function:

$$
R(t ; \eta, \beta, \gamma)=\exp \left[-\left(\frac{t-\gamma}{\eta}\right)^{\beta}\right], \%
$$

- The non-reliability function:

$$
F(t ; \eta, \beta, \gamma)=1-\exp \left[-\left(\frac{t-\gamma}{\eta}\right)^{\beta}\right]
$$

- Intensity or rate of failure:

$$
z(t ; \eta, \beta, \gamma)=\frac{\beta}{\eta}\left(\frac{t-\gamma}{\eta}\right)^{\beta-1}
$$

- Average uptime: 


$$
m=\gamma+\eta \Gamma\left(1+\frac{1}{\beta}\right)
$$

- Median of uptimes:

$$
t_{\text {med }}=\gamma+\eta(-\ln 0,5)^{\frac{1}{\beta}}
$$

In figures 5, 6, 7, 8 these reliability parameters variation are presented.

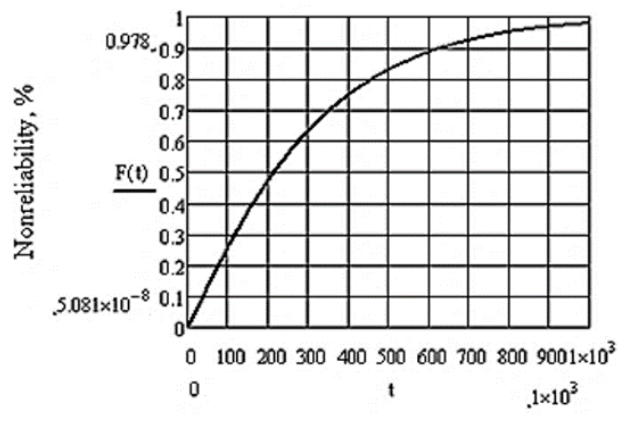

Time, hours

Fig. 5. Variation of the non-reliability function.

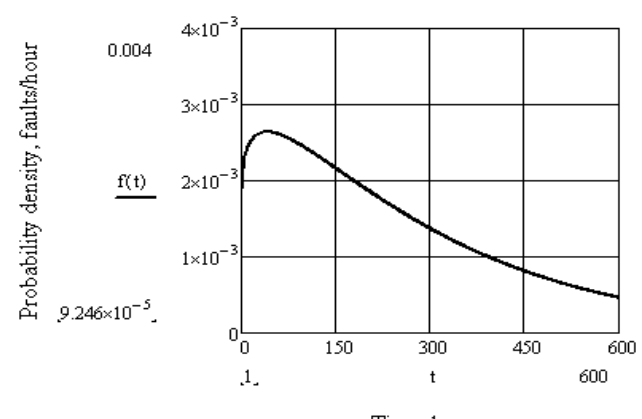

Time, hours

Fig. 6. Probability density of failure occurrence.

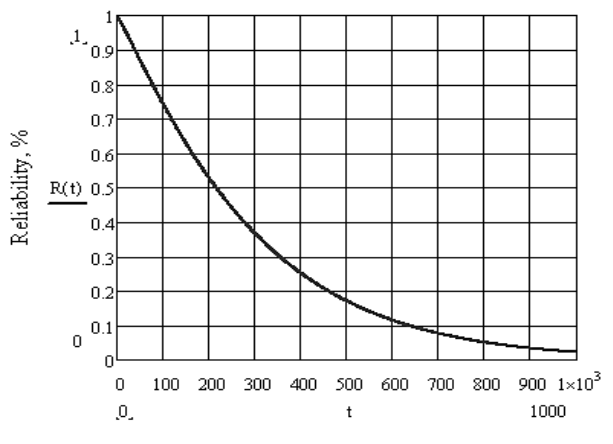

Fig. 6. Variation of the reliability function.

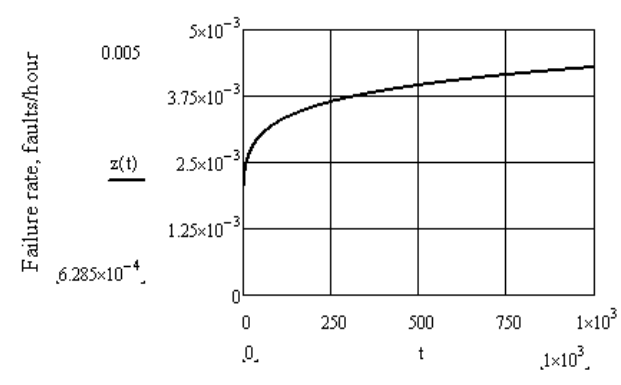

Time, hours

Fig. 7. Failure rate.

\section{Conclusion}

The analysis performed shows that:

The mean time to failure of belt joint is 288 hours, and the median is 216 hours. Considering that the running time is about 20 hours per day, it is expected to have a fault of joint each 14 days. This low reliability is shown by the diagrams above, the probability to not fail after 100 hours, i.e. one week is about $75 \%$. In order to reduce downtimes, the quality of belt joining must be improved, by replacing stapled joints with vulcanized joints. 


\section{References}

1. Ş. Covaci, Exploatări miniere subterane (Ed. Didactică şi Pedagogică, Bucureşti,1983)

2. F.D. Popescu, Proceedings of the 9th WSEAS International Conference Automation And Information (Icai'08), Bucharest, Romania, 120 (2008)

3. G.D. Mihai, I. Kovacs, M.S. Nan, N. Iliaș, I. Andras, S.M. Radu, Proceedings of the 2nd WSEAS International Conference on Engineering Mechanics, Structures and Engineering Geology EMESEG 09, Rodos, Greece (2009)

4. I. Kovacs, S.M. Nan, I. Andraș, G.B. Urdea, Proceedings of the Microcad International Conference (2013)

5. I. Marian, Utilaje de încărcare şi transport minier (Ed. Didactică şi Pedagogică, Bucureşti, 1984) 